\title{
Long-term outcomes in patients with restrictive filling following ST-segment elevation myocardial infarction
}

\author{
L. Hee,$^{1,2}$ X. Brennan, ${ }^{2}$ J. Chen, ${ }^{2}$ C. Allman, ${ }^{1}$ G. A. Whalley, ${ }^{3}$ J. K. French, ${ }^{1,2}$ C. P. Juergens ${ }^{1,2}$ and L. Thomas ${ }^{1,2,4}$ \\ ${ }^{1}$ Cardiology Department, Liverpool Hospital, ${ }^{2}$ South Western Sydney Clinical School, The University of NSW, ${ }^{4}$ Sydney Medical School, The University of \\ Sydney, Sydney, New South Wales, Australia, and ${ }^{3}$ Faculty of Social and Health Sciences, Unitec Institute of Technology, Auckland, New Zealand
}

\section{Key words \\ diastolic dysfunction, ST-segment elevation myocardial infarction, transthoracic \\ echocardiogram, restrictive filling pattern.}

\section{Correspondence}

Liza Thomas, Cardiology Department, Liverpool

Hospital, Elizabeth Street, Sydney, NSW 2170,

Australia.

Email: I.thomas@unsw.edu.au

Received 26 June 2013; accepted 25 November 2013.

doi:10.1111/imj. 12360

\begin{abstract}
This study evaluated the effect of restrictive filling pattern (RFP) on 5-year outcomes in patients following ST-segment elevation myocardial infarction (STEMI). A hundred STEMI patients treated either by rescue or primary percutaneous coronary intervention with an echocardiogram performed within 6 weeks of STEMI comprised the study group. Creatinine kinase (CK) and left ventricular ejection fraction were independent determinants of RFP, and RFP was an independent predictor of cardiac and all-cause mortality at median follow up of 5 years.
\end{abstract}

Percutaneous coronary intervention (PCI), for STsegment elevation myocardial infarction (STEMI), limits myocardial injury and reduces mortality; ${ }^{1}$ however, myocardial damage from STEMI results in systolic and diastolic dysfunction (DD). Although elevated left ventricular (LV) end-diastolic pressure is a predictor of adverse outcome after STEMI, ${ }^{2}$ its invasive nature precludes routine clinical use. Non-invasive estimates of diastolic function, particularly Doppler assessment of LV filling and, more recently, left atrial (LA) volume, have been reported to be predictors of outcome following myocardial infarction (MI). ${ }^{3}$ Previous studies have reported the adverse impact of restrictive filling pattern (RFP) in STEMI patients treated by thrombolysis, demonstrating increased all-cause mortality. ${ }^{4}$ The present study evaluated the impact of RFP on longer term outcomes in STEMI patients treated by PCI. We hypothesised that RFP would remain an independent predictor of longer term outcomes in STEMI patients treated by PCI.

A total of 107 consecutive STEMI patients from Liverpool Hospital, Sydney (January 2003-May 2010), underwent a transthoracic echocardiogram (TTE) (day 3-6 weeks), following STEMI. Patients were excluded for atrial fibrillation $(n=3)$, severe mitral regurgitation $(n=1)$

Funding: None.

Conflict of interest: None. and poor echocardiographic images $(n=3)$. A total of 100 patients (78 males; mean age: $59 \pm 11$ years) comprised the study group, and was treated by rescue $(n=40)$ or primary $(n=60)$ PCI. All patients were clinically stable when the TTE was performed; none had an intra-aortic balloon pump, were on inotropes or in heart failure (HF). All participants had cardiac enzyme evaluation. The study protocol was approved by the Sydney South West Area Health Service ethics committee (QA2009/046).

A comprehensive echocardiogram was performed using commercial equipment (Phillips Sonos 7500, Philips Co, The Netherlands; GE Vivid 7, Horten, Norway) according to standard recommendations. ${ }^{5}$ Transmitral flow was obtained from the apical four-chamber view using pulsed Doppler, and peak E and A velocities, E/A ratio, and deceleration time (DT) were measured. Pulsed tissue Doppler imaging (TDI) from the septal mitral annulus in early diastole $\left(\mathrm{e}^{\prime}\right)$ was evaluated when available $(n=59)$.

LV diastolic function was classified as normal, impaired relaxation, pseudo-normal and restrictive filling based on published criteria; ${ }^{5}$ RFP was defined as E/A ratio $>2$ and/or DT $<140 \mathrm{~ms}^{6}$ Patients $(n=10)$ with indeterminate diastolic grade (i.e. normal vs pseudo-normal filling) were reviewed using A-wave and pulmonary vein A-wave duration and $\mathrm{e}^{\prime}$ velocity. Left ventricular ejection fraction $(\mathrm{LVEF})^{7}$ was measured using the modified biplane Simpson's method; biplane maximum 
LA volume was measured using the area-length method; and LV mass was calculated using the Penn method. ${ }^{8}$ The latter two variables were indexed to body surface area.

Baseline demographic details, cardiac risk factors and discharge medications were obtained from patient records. Duration of ischaemia was measured from symptom onset to establishing TIMI-3 flow. Clinical outcomes, including cardiac death, all-cause death, HF hospitalisation, non-fatal MI, stroke and coronary revascularisation, were tracked for a median of 5 years, from hospital records and/or by telephone follow up from patients or their physicians. Major adverse coronary and cerebral events were a composite of HF, death, MI, stroke or revascularisation.

Analysis was performed using SPSS 19 (SPSS Inc., Chicago, IL, USA) and Stata 12 (StataCorp, College Station, TX, USA). All statistical tests were two-tailed and a $P$ value $<0.05$ was deemed significant. Cumulative survival was constructed by Kaplan-Meier curves, and groups were compared with the log-rank test. A Cox regression analysis was performed for the primary endpoint; variables significant at the bivariate level $(P<0.05)$ or had clinical relevance were included in the model. Multivariate logistic regression analysis was performed to identify independent determinants of RFP.

The study cohort was stratified into restrictive $(n=24)$ and non-restrictive $(n=76)$ groups (Table 1). A higher proportion of patients treated with rescue PCI had RFP (58\% vs $34 \%, P=0.035)$. Age, gender and cardiac risk factors were similar. A significantly higher percentage in the RFP group was discharged on loop diuretics and/or aldactone $(46 \%$ vs $19 \%, P=0.011)$. Higher levels of cardiac enzymes (TnT, CKMB and CK) were found in RFP patients $(P<0.05$ in all $)$ E/A ratio was higher in RFP patients (Table 1). TDI septal $\mathrm{e}^{\prime}$ velocity was reduced in the RFP group, but showed no significant difference. A significantly larger indexed LA volume and a lower LVEF was found in patients with RFP than non-RFP group (43.2 \pm 18 vs $35.8 \pm 11 \mathrm{~mL} / \mathrm{m}^{2}, P=0.017$, and $41.4 \pm 11.5 \%$ vs 48.7 $\pm 8.7 \%, P=0.001$, respectively), whereas indexed LV mass was similar between the groups (Table 1).

Kaplan-Meier analyses demonstrated that both cardiac ( $1 \%$ vs $21 \%, P<0.001$ ) and all-cause death (9\% vs 38\%, $P=0.003$ ) were higher in RFP patients (Fig. S1). There was no significant difference for other end-points (Table S1). Cox regression analysis was performed to investigate the predictive values of clinical and echocardiographic indices on all-cause and cardiac death. Variables included in the model were age, gender, PCI (rescue vs primary), infarct-related variables (TnT, CK, proximal LAD lesion and duration of ischaemia) and echocardiographic indices (LVEF, indexed LV mass and
Table 1 Clinical characteristics and medications at discharge of STEMI

\begin{tabular}{|c|c|c|c|}
\hline & $\begin{array}{l}\text { Non-RFP } \\
(n=76)\end{array}$ & $\begin{array}{c}\text { RFP } \\
(n=24)\end{array}$ & $P$ value \\
\hline \multicolumn{4}{|l|}{ Baseline characteristics } \\
\hline Age - year & $61 \pm 11$ & $57 \pm 10$ & 0.14 \\
\hline Body mass index & $28.4 \pm 6.6$ & $28.3 \pm 4.8$ & 0.90 \\
\hline Male (\%) & $58(76)$ & $20(83)$ & 0.47 \\
\hline Diabetes mellitus (\%) & $26(34)$ & $10(42)$ & 0.51 \\
\hline Prior AMI (\%) & $8(11)$ & $1(4)$ & 0.34 \\
\hline Prior stroke (\%) & $4(5)$ & $2(8)$ & 0.58 \\
\hline Heart failure (\%) & $2(3)$ & $1(4)$ & 0.70 \\
\hline Hypertension† (\%) & $46(61)$ & $13(54)$ & 0.58 \\
\hline Hyperlipidaemiał (\%) & $51(67)$ & $13(54)$ & 0.25 \\
\hline Current smoker (\%) & $46(61)$ & $12(50)$ & 0.36 \\
\hline Chronic kidney disease (\%) & $4(5)$ & 0 & 0.25 \\
\hline \multicolumn{4}{|l|}{$\mathrm{PCl}$ indications } \\
\hline Primary $(n=60)$ & $50(66)$ & $10(42)$ & 0.04 \\
\hline Rescue $(n=40)$ & $26(34)$ & $14(58)$ & \\
\hline \multicolumn{4}{|l|}{ Medication at discharge } \\
\hline Anti-platelets (\%) & $76(100)$ & $24(100)$ & ns \\
\hline Beta-blockers (\%) & $61(80)$ & $20(83)$ & 0.74 \\
\hline Statins (\%) & $59(78)$ & $20(83)$ & 0.55 \\
\hline ARB/ACE inhibitors (\%) & $59(78)$ & $21(88)$ & 0.29 \\
\hline Diuretics (\%) & $15(20)$ & $12(50)$ & $<0.01$ \\
\hline \multicolumn{4}{|l|}{ Markers of infarct size } \\
\hline Peak troponin $\mathrm{T}-\mu \mathrm{g} / \mathrm{L}$ & $6.3 \pm 5.8$ & $9.6 \pm 8.2$ & 0.04 \\
\hline Peak CKMB - $\mu \mathrm{g} / \mathrm{L}$ & $189 \pm 191$ & $312 \pm 248$ & 0.03 \\
\hline Peak CK - U/L & $2011 \pm 1821$ & $4526 \pm 4253$ & $<0.001$ \\
\hline Duration of ischaemia - hr & $7.2 \pm 5.8$ & $8.0 \pm 6.3$ & 0.54 \\
\hline Culprit vessel - Prox LAD (\%) & $33(43)$ & $15(63)$ & 0.10 \\
\hline \multicolumn{4}{|l|}{ Echocardiographic characteristics } \\
\hline Time from STEMI to echo - days & $7 \pm 11$ & $10 \pm 14$ & 0.32 \\
\hline Peak E-wave velocity - m/s & $0.72 \pm 0.19$ & $0.84 \pm 0.21$ & 0.01 \\
\hline Peak A-wave velocity - m/s & $0.68 \pm 0.19$ & $0.53 \pm 0.20$ & 0.001 \\
\hline E/A ratio & $1.1 \pm 0.3$ & $1.9 \pm 1.0$ & $<0.001$ \\
\hline E-deceleration time - ms & $174 \pm 35$ & $132 \pm 11$ & $<0.001$ \\
\hline DTI septal $e^{\prime}-\mathrm{m} / \mathrm{s} \ddagger$ & $6.0 \pm 2.1$ & $5.3 \pm 2.3$ & 0.36 \\
\hline$E / e^{\prime} \neq$ & $12.9 \pm 5.6$ & $22.4 \pm 12.5$ & 0.01 \\
\hline $\mathrm{LA}$ volume index $-\mathrm{mL} / \mathrm{m}^{2}$ & $35.8 \pm 11$ & $43.2 \pm 18$ & 0.02 \\
\hline LVEF - \% & $48.7 \pm 8.7$ & $41.4 \pm 11.5$ & 0.001 \\
\hline LV mass index $-\mathrm{g} / \mathrm{m}^{2}$ & $116 \pm 32$ & $114 \pm 34$ & 0.87 \\
\hline LVEDP - mmHg $\S$ & $24.8 \pm 8.0$ & $30.5 \pm 4.0$ & 0.06 \\
\hline $\begin{array}{l}\text { Mitral regurgitation grade } \\
\text { (mild-moderate) }\end{array}$ & $4(5)$ & $2(8)$ & 0.58 \\
\hline
\end{tabular}

Significant $P$ values were displayed in bold. Data are mean \pm SD or number (percentage); †Arterial pressure $>130 / 85 \mathrm{~mm} \mathrm{Hg}$ or on anti-hypertensive treatment; $¥$ Total cholesterol level $\geq 4.0 \mathrm{mmol} / \mathrm{L}$ or on lipid-lowering treatment. $\ddagger$ Data available in 59 patients; §Data available in 27 patients. ACE, angiotensin-converting enzyme; AMI, acute myocardial infarction; ARB, angiotensin receptor blocker; DTI, Doppler tissue imaging; E/A, early/late diastolic velocity; e', diastolic velocity; LAD, left anterior descending; LV, left ventricular; LVEDP, left ventricular end diastolic pressure; LVEF, left ventricular ejection fraction; RFP, restrictive filling pattern; STEMI, ST-segment elevation myocardial infarction. 
Table 2 Cox and risk multivariate model analyses

\begin{tabular}{lccc}
\hline & HR/OR & $95 \% \mathrm{Cl}$ & $P$ value \\
\hline Cox model: all-cause death & & & \\
$\quad$ Age & 1.13 & $1.04-1.22$ & $<0.01$ \\
$\quad$ RFP & 6.27 & $1.64-24.02$ & $<0.01$ \\
Cox model: cardiac death & & & \\
$\quad$ Age & 1.25 & $1.01-1.53$ & $<0.05$ \\
$\quad$ RFP & 20.72 & $1.38-310.40$ & $<0.05$ \\
Risk model: determinants of RFP & & & \\
$\quad$ CK & 1.32 & $1.07-1.62$ & $<0.01$ \\
$\quad$ LVEF & 0.93 & $0.87-0.99$ & $<0.05$ \\
\hline
\end{tabular}

$\mathrm{Cl}$, confidence interval; $\mathrm{CK}$, creatinine kinase; $\mathrm{HR}$, hazard ratio, used in Cox model; LVEF, left ventricular ejection fraction; OR, odds ratio, used in risk model; RFP, restrictive filling pattern.

LA volume). Only RFP and age were independent predictors of all-cause and cardiac death (Table 2). Independent predictors of RFP determined by multivariate logistic regression analysis (variables included were age, gender, PCI indication, TnT, CK, proximal LAD lesion, duration of ischaemia, LV mass index and LVEF) were CK and LVEF (OR: 95\% CI = 1.32: 1.07-1.62, $P<0.01$, and 0.93: 0.87-0.99, $P<0.05$, respectively).

This study evaluated the impact of RFP on long-term outcomes in STEMI patients treated with PCI; RFP and age were independent predictors of cardiac and all-cause mortality. Restrictive filling was more prevalent in rescue PCI patients, those with higher cardiac biomarker levels, a larger LA volume and a reduced LVEF. On multivariate analysis, CK and LVEF were independent predictors of RFP.

RFP has previously been identified as a predictor of morbidity and mortality in acute myocardial infarction patients. ${ }^{9}$ However, the majority of these reports, including a meta-analysis from $2008,{ }^{10}$ were performed in the era of thrombolytic therapy where TIMI flow status was not ascertained. Patients were heterogeneous, including both STEMI and non-ST segment elevation myocardial infarction patients. Follow up for the majority was 12-24 months, with only 3/16 studies having longer term follow up (4 years). However, the current study examines the impact of RFP in STEMI patients treated by contemporary PCI therapy, which has significantly improved mortality and LVEF. ${ }^{11,12}$

The definition of RFP has been variable; some defined RFP as E/A ratio $>2$, while others used a shortened DT. We defined RFP as E/A ratio $>2$ and/or DT $<140 \mathrm{~ms}$ in all instances. Although current guidelines for the assessment of $\mathrm{LV}$ diastolic function mandates more than $\mathrm{E} / \mathrm{A}$ ratio and DT, transmitral Doppler is robust for determining RFP and has been used by other investigators, including the MERGE HF group ${ }^{4}$ and the European Study Group on Diastolic HF. ${ }^{13}$

Despite the modest size of the group and the low number of events, patients with RFP had increased allcause and cardiac death. Multivariate analysis showed stable numeric estimates for both hazards ratios and 95\% CIs, with significance consistent with univariate analyses results. A previous study demonstrated that RFP at discharge was an independent predictor of mortality. ${ }^{14}$ Therefore, echocardiograms performed immediately post-STEMI may reflect transient LV diastolic dysfunction with subsequent improvement. In this study, as the echocardiograms were performed at variable times (3 days -6 weeks), at worst, we would have underestimated the likely effect of RFP after STEMI.

Approximately $30 \%$ of $\mathrm{HF}$ patients have preserved LVEF and HF due to DD, ${ }^{15}$ with an increasing prevalence with age. ${ }^{16}$ While RFP did not predict HF occurrence (Table 2, $P=0.578$ ), a higher percentage of RFP patients were discharged on diuretics (Table 1). Cardiac biomarkers (CK, CKMB and TnT) are surrogates of infarct size. ${ }^{17-19}$ Significantly higher CK, CKMB and TnT levels were observed in the RFP group, suggesting that a larger infarct predisposed to the development of RFP. In a multivariate analysis, CK was an independent predictor of RFP, similar to a previous study in STEMI patients that demonstrated a correlation between peak CK and infarct size. $^{20}$

There are a several limitations given that this is a single-centre retrospective study with an overall low event rate; nevertheless, we believe our results are clinically important and warrant further study. While the timing of echocardiograms was variable, the percentage of RFP $(\sim 20 \%)$ was similar to that reported in other studies. ${ }^{10}$ Patients with HT and diabetes may have preexisting DD; however, similar proportions of patients with HT and DM were present in RFP and non-RFP groups. We acknowledge that the modest cohort size increases the likelihood of a type 2 error. However, the weight of previous data on the adverse effects of RFP on cardiac outcomes suggest that this is unlikely.

This study demonstrates that RFP was a determinant of cardiac and all-cause mortality at a median follow up of 5 years post-STEMI treated by PCI. While the evaluation of diastolic function following PCI for STEMI is an evolving area, these preliminary results are interesting but require validation in larger patient cohorts. 


\section{References}

1 Thomas D, Giugliano RP. Management of ST-segment elevation myocardial infarction: comparison of the updated guidelines from North America and Europe. Am Heart J 2009; 158: 695-705.

2 Garcia-Rubira JC, Molano F, Espina A, Calvo R, Gonzalez-Valday $M$, Garcia-Martinez JT et al. Abnormal filling pattern of the left ventricle and outcome in acute myocardial infarction. Int J Cardiol 1997; 61: 143-9.

3 Naqvi TZ, Padmanabhan S, Rafii F, Hyuhn HK, Mirocha J. Comparison of usefulness of left ventricular diastolic versus systolic function as a predictor of outcome following primary percutaneous coronary angioplasty for acute myocardial infarction. Am J Cardiol 2006; 97: 160-6.

4 Meta-Analysis Research Group in Echocardiography AMIC, Moller JE, Whalley GA, Dini FL, Doughty RN, Gamble GD, Klein AL et al. Independent prognostic importance of a restrictive left ventricular filling pattern after myocardial infarction: an individual patient meta-analysis: meta-analysis research group in echocardiography acute myocardial infarction. Circulation 2008; 117: 2591-8.

5 Nagueh SF, Appleton CP, Gillebert TC, Marino PN, Oh JK, Smiseth OA et al. Recommendations for the evaluation of left ventricular diastolic function by echocardiography. Eur $J$ Echocardiogr 2009; 10: 165-93.

6 Prasad SB, See V, Brown P, McKay T, Narayan A, Kovoor P et al. Impact of duration of ischemia on left ventricular diastolic properties following reperfusion for acute myocardial infarction. Am

J Cardiol 201 1; 108: 348-54.

7 Hunt SA, Abraham WT, Chin MH, Feldman AM, Francis GS, Ganiats TG et al. 2009 focused update incorporated into the acc/aha 2005 guidelines for the diagnosis and management of heart failure in adults. J Am Coll Cardiol 2009; 53: el-90.

8 Gottdiener JS, Bednarz J, Devereux R, Gardin J, Klein A, Manning WJ et al. American society of echocardiography recommendations for use of echocardiography in clinical trials. J Am Soc Echocardiogr 2004; 17: 1086-119.

9 Cerisano G, Bolognese L, Buonamici P, Valenti R, Carrabba N, Dovellini EV et al. Prognostic implications of restrictive left ventricular filling in reperfused anterior acute myocardial infarction. J Am Coll Cardiol 2001; 37: 793-9.

10 Whalley GA, Gamble GD, Doughty RN. Restrictive diastolic filling predicts death after acute myocardial infarction: systematic review and meta-analysis of prospective studies. Heart 2006; 92: 1588-94.

11 Le May MR, Labinaz M, Davies RF, Marquis JF, Laramée LA, O'Brien ER et al. Stenting versus thrombolysis in acute myocardial infarction trial (stat). $J$ Am Coll Cardiol 2001; 37: 985-91.

12 Świątkiewicz I, Magielski P, Woznicki M, Gierach J, Jabłoński M, Fabiszak T et al. Occurrence and predictors of left ventricular systolic dysfunction at hospital discharge and in long-term follow-up after acute myocardial infarction treated with primary percutaneous coronary intervention. Kardiol Pol 2012; 70: 329-40.
13 Failure ESGoDH. How to diagnose diastolic heart failure. Eur Heart J 1998; 19: 990-1003.

14 Temporelli PL, Giannuzzi P, Nicolosi GL, Latini R, Franzosi MG, Gentile F et al. Doppler-derived mitral deceleration time as a strong prognostic marker of left ventricular remodeling and survival after acute myocardial infarction: results of the gissi-3 echo substudy. J Am Coll Cardiol 2004; 43: 1646-53.

15 Gotsman I, Zwas D, Lotan C, Keren A. Heart failure and preserved left ventricular function: long term clinical outcome. PLOS ONE 2012; 7: e41022.

16 Kitzman DW, Gardin JM, Gottdiener JS, Arnold A, Boineau R, Aurigemma G et al. Importance of heart failure with preserved systolic function in patients $\geq$ 65 years of age. Am J Cardiol 2001; 87: 413-9.

17 Aldous SJ. Cardiac biomarkers in acute myocardial infarction. Int J Cardiol 2013; 164: 282-94.

18 Ingkanisorn WP, Rhoads KL, Aletras AH, Kellman P, Arai AE. Gadolinium delayed enhancement cardiovascular magnetic resonance correlates with clinical measures of myocardial infarction. J Am Coll Cardiol 2004; 43: 2253-9.

19 Ladenson JH. A personal history of markers of myocyte injury [myocardial infarction. Clin Chim Acta 2007;

381: 3-8.

20 Chia S, Senatore F, Raffel OC, Lee H, Wackers FJT, Jang IK. Utility of cardiac biomarkers in predicting infarct size, left ventricular function, and clinical outcome after primary percutaneous coronary intervention for ST-segment elevation myocardial infarction. JACC Cardiovasc Interv 2008; 1: 415-23.

\section{Supporting information}

Additional Supporting Information may be found in the online version of this article at the publisher's web-site:

Figure S1 Cumulative incidence of outcomes among the study patients between RFP and non-RFP groups. KaplanMeier survival curves are shown for (A) cardiac death; (B) all-cause death. $P$ values were calculated using log-rank test.

Table S1 Clinical outcomes at $5 \pm 2$ years follow-up after index STEMI. 